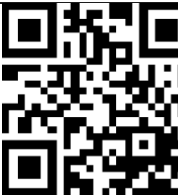

Editor's choice

can to access mo

${ }^{1}$ Hospital Pharmacy of Nord Vaudois and Broye Region, Yverdon-les-Bains, Switzerland

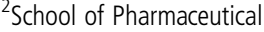

Sciences, University of Geneva,

University of Lausanne,

Geneva, Switzerland

${ }^{3}$ Pharmacy Department,

University Hospitals of Geneva,

Geneva, Switzerland

\section{Correspondence to:}

Clare Béchet, Pharmacie des Hôpitaux du Nord Vaudois et de la Broye, Entremonts 11, Yverdon-les-Bains 1400 , Switzerland;

clare.bechet@phnvb.ch

Received 17 September 2014 Revised 14 January 2015 Accepted 20 January 2015 Published Online First 16 February 2015

CrossMark

To cite: Béchet $C$ Bonnabry P, Pichon R. Eur J Hosp Pharm 2015;22: 267-273.

\title{
Improvement of customer focus in a Swiss regional hospital pharmacy: a mixed method study
}

\author{
Clare Béchet, ${ }^{1,2}$ Pascal Bonnabry, ${ }^{2,3}$ Renaud Pichon ${ }^{1}$
}

\begin{abstract}
Objective To establish how the use of customer feedback could be enhanced within a Swiss regional hospital pharmacy.
\end{abstract}

Methods The study was divided into three parts, each comprising several smaller complementary studies. The first part determined the pharmacy's current way of functioning in relation to customer-focused activities using qualitative methods (pharmacy systematic document research, qualitative interviews and a Strengths, Weaknesses, Opportunities and Threats (SWOT) analysis). The second part was designed to define the requirements related to an optimal customerfocused quality management system (QMS); these were obtained from two quality standards (ISO 9001 and the Référentiel Qualité pour la Pharmacie Hospitalière), Swiss laws, the pharmacy staff and other organisations. In the third part these requirements were cross-checked (mostly in a qualitative way) against observations of the current functioning in order to generate suggestions for improvement. A quantitative quality self-assessment was carried out to evaluate the pharmacy's response to the quality requirements and to prioritise the ones that needed to be improved.

Results The first part revealed that the methods used to collect information about customer requirements and satisfaction were sparse and that the internal structure, procedures and employee knowledge were also insufficient. The second part brought into focus the importance for all pharmacy employees to share the same understanding of customer feedback in order to develop a customer-focused QMS. In the last part, numerous suggestions for improvement were made. These included developing tools to collect customer feedback, establishing a systematic analysis of customer feedback for decision making, and developing a corporate culture and providing appropriate training to develop the knowledge and skills of employees.

Conclusions Weaknesses concerning the functioning of the entire pharmacy were identified and many suggestions for improvement of the pharmacy's functioning in relation to customer focus were made. The results of this study indicate that employee knowledge and involvement are paramount to the success of a customer-focused QMS. It is considered critical that all staff should share the same understanding and aim. Thus, training and active involvement of pharmacy employees is regarded as fundamental to the success of a new system.

\section{INTRODUCTION}

To ensure the quality and security of their services and also to meet Swiss health legislation which states that healthcare providers must develop quality programmes, hospital pharmacies as well as a large percentage of Swiss healthcare organisations often obtain certification of their quality management system (QMS) by a quality management standard such as International Organization for Standardization (ISO) 9001. By doing so, proof of the quality of pharmaceutical services is also provided-for example, for health insurances which only recognise and therefore pay for services with proven quality. $^{1-4}$

Customer focus is an important requirement of the ISO 9001:2008 standard and of a Swiss hospital pharmacy quality standard, the Référentiel Qualité pour la Pharmacie Hospitalière (RQPH: 2009), developed by the Swiss Association of Public Health Administration and Hospital Pharmacists (GSASA, http://www.gsasa.ch). ${ }^{5}$ It is also one of the eight ISO 9000:2005 quality management principles. ${ }^{7}$ These standards state that customer requirements should be determined and met by organisations in order to continually improve customer satisfaction. This requirement is established on the principle that 'organisations depend on their customers and therefore should understand current and future customer needs, should meet customer requirements and strive to exceed customer expectations'?

The literature has shown the critical importance of customer satisfaction for organisations. A correlation has been clearly shown to exist between customer satisfaction, corporate image, customer loyalty and development, profitability and sustainability of companies. It is always customers who determine the acceptability of all products and services that a company offers. ${ }^{8-17}$

In a Swiss regional hospital pharmacy an accreditation organisation stated repeatedly that customer focus was insufficiently developed. As this hospital pharmacy is independent from its customers (an explanation of 'customers' can be found below), a lack of customer focus could have serious repercussions on ensuring its continued existence. Furthermore, responding to customer requirements is critical as the pharmacy's environment is currently subject to multiple changes. A Diagnosis Related Groups system of reimbursement, which has recently been implemented in Switzerland, has obliged the hospital to reduce costs and become more efficient. ${ }^{18}$ In addition, most of this pharmacy's hospital customers have recently hired new directors, who probably have different needs and expectations from their predecessors. The services currently offered by the pharmacy might not be those needed, possibly not all requirements are being met and customers may no longer be satisfied with this collaboration.

The aim of this study was to identify the weaknesses in the current system in order to formulate 
suggestions for improving consideration of customer feedback within this organisation. The study also aimed to increase concordance between pharmacy activities and quality standard requirements from ISO 9001 and RQPH in terms of customer focus and continuous improvement by taking customer feedback further into account.

\section{METHODS}

\section{Setting}

The Pharmacie des Hôpitaux du Nord Vaudois et de la Broye is a regional central pharmacy that was founded to supply nine different hospitals, a nursing home for the elderly and an ambulance service, all of which are situated within a local geographical area of north-west Switzerland. It is a non-profit organisation that is legally independent from the organisations to which it supplies services.

The pharmacy services include choosing, buying, storing and dispensing drugs and some medical devices to care units and patients, compounding drugs (as well as sterile products such as chemotherapies) and also advising healthcare professionals and patients on the safe, effective and efficient use of drugs by means of clinical pharmacy and pharmaceutical assistance.

The pharmacy's customers include all of the organisations to which the pharmacy provides services as entities in their own right. The word 'customer' also includes all the staff who work in these organisations (all the healthcare staff as well as other professionals such as the company's management). The pharmacy's customers also include patients who are cared for in these institutions. Some patients, such as those in nursing homes, are direct pharmacy customers. The hospital pharmacy delivers the medication to these patients individually and bills directly to their health insurers. There are therefore different levels of customers who can be considered simultaneously.

The study was divided into three separate parts (figure 1).

\section{Part 1: Evaluating the situation}

The first part aimed to determine the pharmacy's current way of functioning in relation to customer-focused activities. It was decided to use several methods in order to gather complementary information about the existing system. Systematic research was carried out throughout various pharmacy documents (referenced procedures (47) and documents (188), annual management review minutes, annual reports, external and internal audit reports) to retrieve official organisation information about client-focused activities. All documents were investigated by the
Project Leader (CB). The data gathered were entered in a preestablished table (one row for every potential customer listening tool and a column for every observation made during the documentary research). The findings were approved by the Chief Pharmacist as the main reliability check (peer review). A keyword search was also performed on Optimiso to make sure that all customer-focused activities had been identified. Optimiso software allows organisations to map, manage and communicate different kinds of internal documentation. The pharmacy's procedures and documents are all referenced on this software.

Optional semi-structured interviews lasting $20 \mathrm{~min}$ were carried out with one-third of the pharmacy's employees $(6 / 19$ employees) by the Project Leader. These interviews aimed to provide information about real activities, workers' knowledge and understanding concerning client focus and also about their willingness to improve the current way of functioning (level of satisfaction with current system). The employees were selected to represent each age group and type of profession available in the hospital pharmacy. The sample size was a compromise between sufficient data collection to achieve the aim of the interviews, limitation of bias (representative sample) and efficiency (time-consuming). The answers were recorded by notetaking during and after the interviews. The collected data were mostly analysed in a deductive way based on the aims of the interviews. Additional themes that had not been initially planned but that arose from the collected data were also taken into account. The answers given by the different participants were compared, and particular attention was given to the similarities and differences between the answers of each participant.

All the information gathered was then used by the Project Leader to carry out a SWOT analysis (Strengths, Weaknesses, Opportunities and Threats) of the pharmacy's existing system with reference to customer focus. ${ }^{19}$

\section{Part 2: Defining the requirements}

The second part was designed to define the requirements related to an optimal customer-focused QMS as well as the needs and expectations of the pharmacy's employees. Requirements related to an optimal customer-focused QMS were obtained by research into Swiss law and ISO 9001 and RQPH quality standards. The needs and expectations of the same six pharmacy employees questioned in Part 1 were then determined by optional semi-structured interviews (see Part 1). The employees were divided into three groups depending on

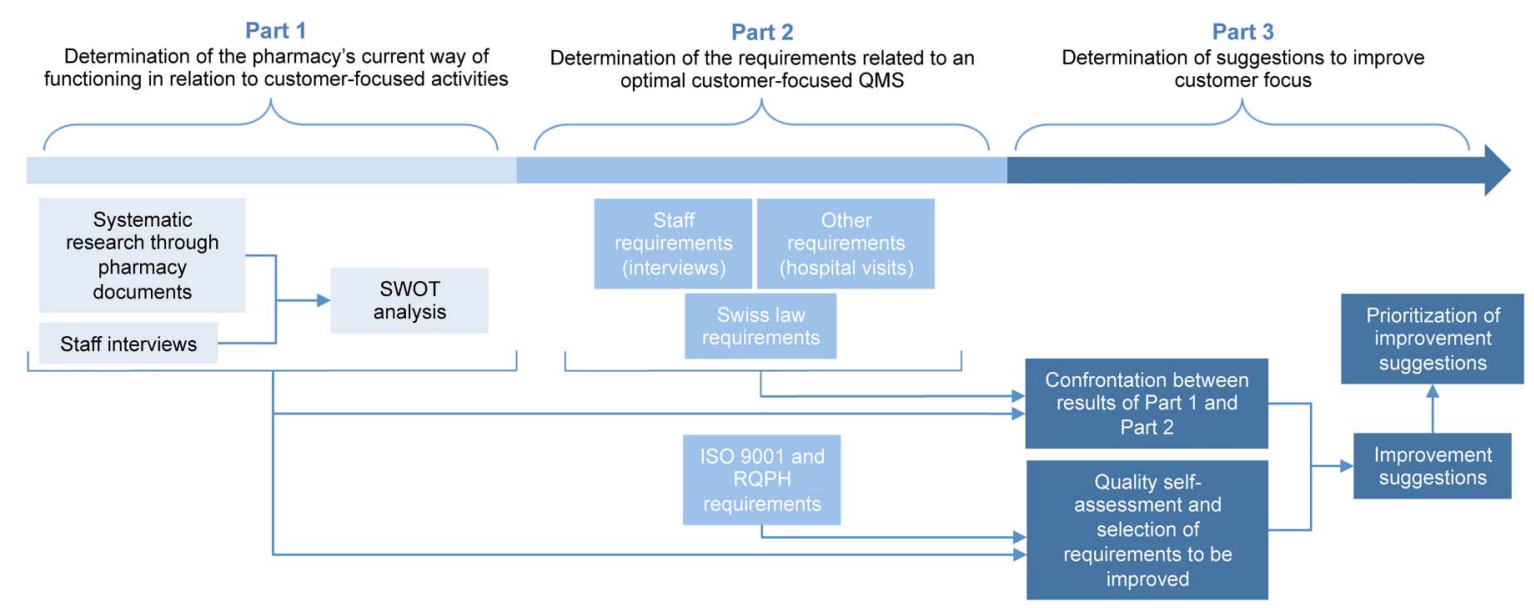

Figure 1 Study design. SWOT, Strengths, Weaknesses, Opportunities and Threats. 
their use of a customer-focused QMS system. Some employees are users of the information resulting from the data collection (eg, process managers), others are mostly in charge of the treatment of complaints and improvement suggestions (eg, quality officer, incident manager) while other employees provide data input. These groups were established to highlight important requirements relevant to different types of users. The needs and expectations of staff were considered critical as the system must, above all, be useful, usable and, of course, used by them. Some further requirements were also identified from visits to four hospitals.

\section{Part 3: Suggesting improvements}

In the third part, suggestions were made for improving customer focus awareness. The requirements identified in Part 2 were systematically cross-checked against the results obtained in Part 1 in order to make constructive and concrete suggestions for improving customer focus. These were approved by the management of the pharmacy, which helped ensure their validity (peer review as main reliability check). Then, as improvement of the concordance between quality standards and pharmacy activities is considered to be an aim of this study, a self-assessment was carried out by a three-person working group (composed of the Quality Assurance Manager, the Chief Pharmacist and the Project Leader) to cross-check the quality standard specifications against current functioning findings. This method was used to ensure an objective and thorough evaluation. It was also used to prioritise the requirements for improvement. The work task evaluated all the quality requirements previously identified (general and specific requirements separately) according to four criteria: the current level of realisation of the requirement; the extent of measurements performed for that criterion; the suitability of the answer to the requirement; and its relevance to the organisation. Each criterion was given a score of $0-3$ points depending on its level of realisation, measurement, suitability and relevance, respectively ( 0 being a non-existent response and 3 being an optimal response). By adding these four scores, a total score of maturity was then obtained for each quality requirement. A total maturity score of 0-4 points was considered as insufficient and needing immediate improvements; a final score of 5-8 points was evaluated as an intermediate level of response to the requirement; and a score of 9-12 points was considered as being adequate. This method was developed by the working group based on scales used by ISO for self-assessment which were adapted to the pharmacy's needs. ${ }^{20}$ The three working group participants scored the requirements separately, and the scores were subsequently compared and a consensus was sought. This comparison step was a means used to ensure the validity and reliability of the self-assessment results. All the requirements with a total maturity score of $<5$ points were selected for improvement. The requirements that obtained 0 points for any of the four criteria and those that obtained 1 point for their degree of realisation were also selected for improvement suggestions. These cut-off values were a compromise between making sure that requirements needing improvement in priority were not missed out and being sufficiently selective to discriminate between the most important requirements and those not requiring improvement. Finally, all the improvement suggestions made in Part 3 were prioritised depending on the ease, speed and cost of their implementation, the human resources required, the expected level of impact, the company's values and missions, and the pharmacy's environment and context.

\section{RESULTS}

\section{Part 1: Evaluating the situation}

The systematic research of the documentation identified several means used to collect customer feedback. Customer satisfaction surveys are carried out about every 2 years (paper form with identical global questions). A form is also used by clients to request drug changes on the hospital drug list and another one in case of delivery errors. The pharmacy's employees can complete a form to report incidents, risks, improvement suggestions and non-conformities. This form can also be used by employees to record client complaints, although it is rarely used in this way. Focus groups or meetings are sometimes used to define the needs and expectations of clients, but without traceability of discussed matters or valorisation of these customer-focused activities. Finally, a few indicators are also used to monitor parameters directly or indirectly illustrating client satisfaction. Although there are several client-focused activities, these were very difficult to find in the pharmacy's QMS and documents. They are not centralised, but spread throughout the pharmacy's processes and activities. Very little information about customer satisfaction or requirements is available in the management review and for process management. The keyword research emphasised a lack of presence and definition of customerfocused activities in the QMS as no results were obtained for words such as 'customer listening' or 'customer feedback'.

Staff interviews revealed gaps in most employees' knowledge about customer focus, although the levels of knowledge among pharmacy employees varied. The employees principally thought of customer-focused activities as dealing with everyday complaints and dissatisfaction. Their answers mostly excluded active information-seeking such as surveys, meetings and market analysis, as well as indirect methods of collecting information about customer satisfaction such as indicators or employee feedback. They omitted the importance of notifying and collecting the generated information and only focused on dealing with the actual complaints. The employees also neglected the importance of identifying customers' requirements. Difficulty in identifying customer feedback was described by some employees. In practice, they found it difficult to identify complaints as, contrary to common belief, they are often made with a smile. Other customer feedback was also reported to be difficult to identify as being useful and needing to be collected-for example, a discussion with a customer met by chance that can be very informative but is rarely reported. The pharmacy employees globally answered that more notice should be taken of customers' needs and expectations in order to help pharmacy activities work better and to reduce the number of everyday problems.

The results of the SWOT analysis are shown in table 1 .

\section{Part 2: Defining the requirements}

There are many specifications that need to be taken into account when setting up an optimal customer-focused QMS. Swiss laws require hospital pharmacies to have a QMS, but do not provide specific guidance or indications on how to do so. The law requires pharmacists to notify the competent authority of any serious reaction or event linked with a drug. It also states that pharmacies should have a complaint and incident processing system in place that should result in measures to be taken. Some of these measures, such as batch recalling, must have clear known procedural stages. All steps should also be taken to prevent any recurrence of incidents. ${ }^{1} 22122$

In total, over 50 global and specific requirements concerning customer focus and feedback and continual improvements were 
Table 1 Pharmacie des Hôpitaux du Nord Vaudois et de la Broye (PHNVB) customer focus SWOT analysis results

$\begin{array}{lll}\text { Strengths Weaknesses } & \end{array}$

- The hospital pharmacy is ISO 9001 and RQPH certified and has a functioning QMS.

- Several tools have already been implemented and are currently used to gather information about customers' requirements and satisfaction (satisfaction enquiries, audits, improvement forms, work tasks, indicators, incident reporting management).

- Several pharmacy employees have been trained for incident management and as auditors and are familiar with QMS and continual improvement.

- The PHNVB's Chief Pharmacist has recently been hired.

- The assignments and objectives of this hospital pharmacy are being redefined, thus taking into consideration customer interests and requirements. The new director is concerned and interested in improving client focus and collecting customer feedback.
- The existing system is incomplete (only few tools available and rarely used to listen to customers' requirements).

- Customers' needs and expectations are little known. No market research has ever been carried out.

- Incident reporting is unevenly available (only available to one hospital customer and to the pharmacy's employees).

- The current corporate culture is not very client-focused.

- Most pharmacy employees are not well trained and have little knowledge about quality, and more specifically about customer focus and the tools that are available to determine their needs and requirements.

- There is a lack of coherence between the production of information and its use by the pharmacy's management. There is little gathering, centralisation and traceability of most of the customer information that is available.

\section{Opportunities}

Threats

- The recent changes in the pharmacy's environment reinforce the need to develop an optimal customer-focused QMS (new hospital financial system remuneration, new management in all three client hospital complexes).
- The recent change in the pharmacy's management has already led to many changes. Further modifications might not be well accepted by employees and could be difficult to implement.

- The present financial environment is difficult and might be an obstacle to developing activities and hiring extra staff. Projects with an immediate return on investments might be preferred to this one.

- Weaknesses in the pharmacy's QMS with regard to customer focus have been identified at each of the last three recertification audits. An improvement in the situation has become necessary and more pressing to avoid receiving a non-conformity during the next audit.

QMS, quality management system; RQPH, Référentiel Qualité pour la Pharmacie Hospitalière; SWOT, Strengths, Weaknesses, Opportunities and Threats.

identified in ISO 9001 and RQPH quality standards. They broadly state that the organisation manager must communicate the importance of satisfying customers' requirements and must ensure that customer needs and expectations are known and fulfilled in order to improve their satisfaction. The management review inputs must include information on customer feedback, and its outputs must include improvement of product-related customer requirements. The resources necessary must be determined and provided in order to be able to enhance customer satisfaction by meeting customer requirements and by continually improving the system's effectiveness. Customer satisfaction must be monitored as one of the performance measurements of the QMS. Effective arrangements for communicating with customers on product information, enquiries, contracts and about customer feedback (including customer complaints) must have been determined and implemented. Appropriate data must have been determined, collected and analysed to demonstrate the suitability and effectiveness of the QMS, and to provide information on customer satisfaction and conformity to product requirements. These quality standards also have several requirements concerning continual improvement and implementation of preventive and corrective actions. $^{5} 6$

The interviews with pharmacy staff revealed important differences between the requirements of the three groups considered. Employees providing data for the system had very few requirements or suggestions compared with the other employee groups and basically were only interested in having better feedback about these activities. Employees in charge of the treatment of complaints and improvement suggestions stressed the importance of an easy-to-use system, with requirements such as a computerised centralised system, clear procedural stages and a designated manager. Employees who are users of the information resulting from data collection requested that every single pharmacy unit should incorporate client-focused activities and highlighted that an integrated system was preferable and that a better gathering of the generated information was needed for decision making.

Other requirements were found when visiting other organisations, such as the importance of clearly defining that the implemented functioning must be system-orientated and not based on individual performance. It must be non-punitive (except in cases of explicit violation of procedures), anonymous reporting should be possible, and transparency should be ensured in the processing and accessibility available to the notifier. The processing should be systematic and result in concrete constructible solution implementation and continual improvement. Notifiers, staff and customers should be informed of changes made and of the outcomes of this QMS in order to encourage notifying and information collecting. The system should be designed to guarantee its sustainable profitability (in comparison with costs due to non-conformities, claims or dissatisfaction). Dedicated software is an advantage when there is a significant amount of data to collect and process. The system must remain simple to use and be easily accessible to all users. Employee knowledge, understanding and implications are crucial to its good functioning.

\section{Part 3: Suggesting improvements}

No significant differences were detected during the comparison and pooling step, and the working group participants were able to agree without difficulty on common scores for all requirements and each criterion. For the quality self-assessment, the pharmacy obtained on average total maturity score between 7 (ISO 9001) and 7.5 points (RQPH) out of 12 points, indicating an intermediate global maturity of the QMS concerning customer focus. Eighteen requirements were selected according to the predefined criteria for improvement suggestions (4/14 from ISO 9001 and 14/40 from RQPH; table 2). Most of these requirements scored more points for their level of realisation and measurement and fewer points on their level of suitability and relevance to the pharmacy (table 3 ). 
Table 2 Quality self-assessment results

\begin{tabular}{|c|c|c|c|c|c|c|c|}
\hline \multirow[b]{2}{*}{$\begin{array}{l}\text { Quality } \\
\text { standard }\end{array}$} & \multirow[b]{2}{*}{ Requirement } & & \multicolumn{5}{|l|}{ Score } \\
\hline & & & $\begin{array}{l}\text { Total } \\
\text { maturity }\end{array}$ & Realisation & Measurement & Suitability & Relevance \\
\hline RQPH & Rights and respect of patients & 1.1 & 4 & 1 & 0 & 1 & 2 \\
\hline 40 items & Security and risk concept & 1.3 & 8 & 2 & 2 & 2 & 2 \\
\hline \multirow[t]{40}{*}{ scored $^{*}$} & & 1.3 a) & 7 & 2 & 1 & 2 & 2 \\
\hline & & $1.3 \mathrm{~b})$ & 10 & 3 & 3 & 1 & 3 \\
\hline & Drug list & 1.5 .1 & 9 & 3 & 3 & 2 & 1 \\
\hline & & 1.5.1 b) & 10 & 3 & 3 & 3 & 1 \\
\hline & & $1.5 .1 \mathrm{c})$ & 9 & 3 & 3 & 2 & 1 \\
\hline & Drug manufacturing & $1.5 .2 \mathrm{~d})$ & 9 & 3 & 3 & 1 & 2 \\
\hline & Information and advice & $1.5 .4 \mathrm{c})$ & 4 & 1 & 1 & 1 & 1 \\
\hline & Concept of continuous improvement & 1.8 .1 & 10 & 3 & 3 & 2 & 2 \\
\hline & & 1.8.1 a) & 9 & 2 & 3 & 2 & 2 \\
\hline & Complaint management & 1.8 .2 & 2 & 1 & 1 & 0 & 0 \\
\hline & & 1.8.2 a) & 2 & 1 & 1 & 0 & 0 \\
\hline & & $1.8 .2 \mathrm{~b})$ & 2 & 1 & 1 & 0 & 0 \\
\hline & & $1.8 .2 \mathrm{c})$ & 2 & 1 & 1 & 0 & 0 \\
\hline & & $1.8 .2 \mathrm{~d})$ & 2 & 1 & 1 & 0 & 0 \\
\hline & Improvement suggestions & 1.8.3† & 11 & 3 & 3 & 3 & 3 \\
\hline & & & 6 & 2 & 2 & 1 & 1 \\
\hline & & 1.8.3 a) & 11 & 3 & 3 & 3 & 2 \\
\hline & & $1.8 .3 \mathrm{~b})$ & 11 & 3 & 3 & 3 & 2 \\
\hline & & $1.8 .3 \mathrm{c})$ & 8 & 3 & 3 & 1 & 1 \\
\hline & & $1.8 .3 \mathrm{~d})$ & 4 & 1 & 0 & 2 & 1 \\
\hline & Pharmacy policy & 3.2 .1 & 7 & 3 & 0 & 3 & 1 \\
\hline & Management commitment & 3.2 .2 & 11 & 3 & 2 & 3 & 3 \\
\hline & & $3.2 .2 \mathrm{c})$ & 12 & 3 & 3 & 3 & 3 \\
\hline & Customer requirements & 3.2 .3 & 5 & 1 & 1 & 2 & 1 \\
\hline & Management of change & $3.2 .6 \mathrm{~b})$ & 4 & 1 & 0 & 3 & 0 \\
\hline & Management review & 3.3 .2 & 7 & 2 & 3 & 1 & 1 \\
\hline & Measurement of customer and staff satisfaction & 3.3 .3 & 9 & 3 & 3 & 2 & 1 \\
\hline & & 3.3 .3 a) & 6 & 3 & 3 & 0 & 0 \\
\hline & & 3.3 .3 b) & 10 & 3 & 3 & 2 & 2 \\
\hline & & $3.3 .3 \mathrm{c})$ & 10 & 3 & 3 & 3 & 1 \\
\hline & & $3.3 .3 \mathrm{~d})$ & 9 & 2 & 3 & 3 & 1 \\
\hline & Management of non-conformities & 3.3 .5 & 9 & 2 & 3 & 2 & 2 \\
\hline & & 3.3 .5 a) & 9 & 2 & 3 & 3 & 1 \\
\hline & & $3.3 .5 \mathrm{~b})$ & 7 & 2 & 3 & 1 & 1 \\
\hline & Preventive and corrective actions & 3.3 .6 & 8 & 2 & 3 & 2 & 1 \\
\hline & & 3.3.6 a) & 2 & 1 & 0 & 1 & 0 \\
\hline & & 3.3 .6 b) & 2 & 1 & 0 & 1 & 0 \\
\hline & Measurement of improvement in the quality & 3.4 & 8 & 3 & 3 & 1 & 1 \\
\hline & management system & $3.4 \mathrm{~d})$ & 3 & 1 & 1 & 1 & 0 \\
\hline & Mean RQPH score & & 7 & 2.12 & 2.05 & 1.66 & 1.17 \\
\hline ISO 9001 & Management commitment & 5.1 & 9 & 2 & 3 & 2 & 2 \\
\hline \multirow[t]{15}{*}{14 items scored } & Customer focus & 5.2 & 6 & 1 & 2 & 2 & 1 \\
\hline & Management representative & 5.5 .2 & 12 & 3 & 3 & 3 & 3 \\
\hline & Management review input & 5.6 .2 & 6 & 1 & 3 & 1 & 1 \\
\hline & Management review output & 5.6 .3 & 6 & 1 & 3 & 1 & 1 \\
\hline & Provision of resources & 6.1 & 6 & 2 & 1 & 2 & 1 \\
\hline & Determination of requirements related to products & 7.2.1 & 5 & 1 & 1 & 1 & 2 \\
\hline & Customer communication & 7.2 .3 & 5 & 2 & 1 & 1 & 1 \\
\hline & General & 8.1 & 8 & 3 & 3 & 1 & 1 \\
\hline & Customer satisfaction & 8.2 .1 & 9 & 3 & 3 & 2 & 1 \\
\hline & Data analysis & 8.4 & 7 & 2 & 2 & 2 & 1 \\
\hline & Continuous improvement & 8.5 .1 & 10 & 3 & 3 & 2 & 2 \\
\hline & Corrective actions & 8.5 .2 & 8 & 2 & 3 & 2 & 1 \\
\hline & Preventive actions & 8.5 .3 & 8 & 2 & 3 & 2 & 1 \\
\hline & Mean ISO 9001 score & & 7.5 & 2 & 2.43 & 1.71 & 1.36 \\
\hline & Mean global score & & 7.25 & 2.06 & 2.24 & 1.69 & 1.26 \\
\hline
\end{tabular}

The requirements selected for improvement suggestions are shown in bold type.

*General requirements (14) and specific requirements were analysed separately (26).

†The internal functioning (employees) and the outside functioning (customers) were scored separately because they were too different and no other agreement could be found within the working group.

RQPH, Référentiel Qualité pour la Pharmacie Hospitalière.

In total, 56 suggestions were made. These ranged from very general suggestions to much more specific ones in relation to particular pharmacy activities and documents. The suggestions were prioritised and the Chief Pharmacist incorporated the three most important global suggestions in the pharmacy's strategic objectives for the next 4 years. These included developing tools to collect customer feedback about their needs, expectations and satisfaction; establishing a systematic analysis of 


\begin{tabular}{|c|c|c|c|c|}
\hline \multirow[b]{2}{*}{ Score } & \multicolumn{4}{|l|}{ Criterion } \\
\hline & Realisation & Measurement & Suitability & Relevance \\
\hline 0 & 0 & 6 & 7 & 10 \\
\hline 1 & 17 & 12 & 16 & 27 \\
\hline 2 & 16 & 5 & 20 & 14 \\
\hline 3 & 22 & 32 & 12 & 4 \\
\hline
\end{tabular}

customers' requirements and satisfaction for process managing; and developing a corporate culture of customer focus and providing appropriate training to develop the knowledge and skills of employees. The more specific suggestions related to completing report forms to ensure follow-up and to involve different pharmacy employees in their execution.

\section{DISCUSSION}

The aim of this study was to identify how to improve customer focus and to take more account of customer feedback.

\section{Main findings}

In Part 1 the first key observation was that very few tools were available to define and collect customer feedback, and therefore little was known about their needs, expectations and satisfaction. The second major observation was that customer focus, its purpose and the tools used to collect information about their requirements and satisfaction had not been defined. In addition, the pharmacy's culture lacked customer awareness and pharmacy staff lacked knowledge about customer feedback. The few activities used to gather customer feedback were therefore employed probably mostly by chance or merely to answer specific quality requirements. The resulting information was therefore generally not collected and not used for decision making. Part 1 was very valuable as it showed that weaknesses concerned the functioning of the entire pharmacy and not only the lack of tools used to collect customer feedback, as was initially thought.

Part 2 revealed that there were significant differences between the knowledge and expectations of pharmacy employees. This finding emphasised the need to establish a common corporate culture and better knowledge among employees so that all staff share the same understanding, interest and-most important of all-the same aim in order to develop a better functioning customer-focused QMS.

Part 3 showed that most quality requirements scored more points on their level of realisation and measurement and fewer points on their level of suitability and relevance to the pharmacy. This supports the idea that a number of customer-focused activities had been put in place or measured merely to respond to a quality requirement without being especially useful to the pharmacy. The fact that the pharmacy's QMS answered ISO requirements slightly better than RQPH requirements was probably due to the fact that ISO 9001 was implemented first and has more global requirements than RQPH (ie, hospital pharmacy-orientated).

\section{Weaknesses of the study}

The study's main weakness is the fact that the results are mostly qualitative and were obtained, interpreted and commented on by a single person within the company (CB). They may therefore be subject to some bias. However, different methods and a working group were used throughout the study in order to be as rigorous and objective as possible. The intermediate and final results and their interpretation were approved by the management of the pharmacy, which also helped ensure their validity. Another limitation of this work is that it is based on findings made at a given time whereas the activities of the pharmacy have been in constant change, especially since a new Chief Pharmacist was hired.

\section{Comparison with other studies}

The fact that customer feedback information was not collected and not used for decision making is an issue that has also been described in another study which found that questionnaire results performed in French hospitals did not lead to changes in patient management. This observation led to improving the questionnaire by adding an indicator that would enable monitoring of the number of changes made in procedures. ${ }^{25}$ In contrast, in this study it was decided that improving tools used to collect customer feedback, even if they are currently poorly developed or not necessarily adequate, would initially be counterproductive. The necessity to create a need and an understanding for the use of customer feedback among the employees of the pharmacy was considered to be of greater importance.

The need to establish a common corporate culture and better knowledge among the employees so that all staff share the same understanding, interest and aim in order to develop a better functioning customer-focused QMS is in agreement with the principle of ISO 9001:2008 concerning the involvement of people, and is also developed in ISO 10018:2012. ${ }^{62324}$

\section{Study impact}

This study provides practical information for evaluating and improving customer focus. Although it was carried out in an independent regional hospital pharmacy, its results could be useful to other pharmacies or even other organisations. Customer-focused QMS are essential to any company, and the results of this study indicate that employee knowledge and involvement is a key to their success. This study also highlighted the importance of addressing the use of customer feedback within the organisation and how this information can be taken into account by management.

\section{Further work}

As a follow-up, the selected improvement suggestions will be gradually implemented over the next 4 years. Moreover, in this study it was decided to seek only the employees' opinions as it was considered more important to improve the internal working of the company than to implement better means of gathering customer feedback. However, customer expectations should subsequently be sought as their requirements would be profitable to the improvement of customer feedback tools. Furthermore, the requirements for an optimal customer-focused QMS will have to be updated to comply with the ISO 9001:2015 version. Finally, in the longer term and after having implemented improvement suggestions, the functioning of the pharmacy in relation to customer focus should be evaluated to determine whether the objectives have been achieved (in a continuous improvement strategy).

\section{CONCLUSION}

Customer focus is a cross-functional and multidisciplinary activity that concerns the whole pharmacy and its entire staff. The results of this study indicate that employee knowledge and involvement are paramount to the success of customer-focused QMS. This study emphasises the importance of addressing 
customer feedback within an organisation. The information thus generated can then be considered by decision makers which, to date, has not always been the case. It is essential that employees understand the purpose of customer focus and how the information gathered about their requirements and satisfaction can be used for the pharmacy's management.

Key messages

What is already known on this subject

- It is well recognised that customer feedback is a very valuable source of information for an organisation. It provides input for continual improvement and also enables organisations to improve customer satisfaction. A correlation has been clearly shown to exist between customer satisfaction, corporate image, customer loyalty and development, profitability and sustainability of companies.

\section{What this study adds}

- Customer focus should be an integrated system as it is a multidisciplinary and cross-functional activity. It should further be kept in mind that its success depends on the capacity of the organisation to collect information about customer requirements and satisfaction, and also on its capacity to use these data for management decisions and continuous improvement. It is therefore essential that employees understand the purpose of customer focus and how customer feedback can be collected and used for the pharmacy's management.

Acknowledgements The authors thank all the hospital collaborators (from PHNVB, HUG, eHnv, CSSC and HIB) for their input for Part 2 of the study.

Contributors $C B$ was responsible for the conception and design of the study: acquisition, analysis and interpretation of data; and drafting the article. RP supervised and revised the conception of the study and approved the results and manuscript. PB reviewed and commented on the final manuscript.

\section{Competing interests None.}

Provenance and peer review Not commissioned; externally peer reviewed.

\section{REFERENCES}

1 Loi fédérale sur les médicaments et les dispositifs médicaux (LPTh); RS 812.21. Le Conseil fédéral suisse, 2000.
2 Swissmedic. Pharmacopoea Helvetica, 11 edn, 2012

3 Ordonnance sur l'assurance-maladie (OAMal); RS 832.102. Le Conseil fédéral suisse, 1995.

4 Loi fédérale sur l'assurance-maladie (LAMal); RS 832.10. L'Assemblée fédérale de la Confédération suisse, 1994

5 Référentiel Qualité pour la Pharmacie Hospitalière (RQPH). GSASA et APEQ, 2009.

6 ISO 9001. Quality management systems-Requirements. Geneva: International Organization for Standardization, 2008.

7 ISO 9000. Quality management systems-Fundamentals and vocabulary. Geneva: International Organization for Standardization, 2005.

8 Association Française de Normalisation. Management de la qualité-Guide pour I'identification des exigences des clients. FD X 50-179. La Plaine Saint-Denis: Association Française de Normalisation (AFNOR), 2000.

9 ISO/TS 10004. Quality management-Customer satisfaction-Guidelines for monitoring and measuring. Geneva: International Organization for Standardization, 2010.

10 Barouch G. Fidéliser et gagner vos clients par l'écoute. La Plaine Saint-Denis: Association Française de Normalisation (AFNOR), 2010.

11 Millot S. L'enquête de satisfaction. La Plaine Saint-Denis: Association Française de Normalisation (AFNOR), 2007

12 Hermel L. Stratégie de gestion des réclamations clients. La Plaine Saint Denis: Association Française de Normalisation (AFNOR), 2006.

13 Jones T, Sasser E. Why satisfied customers defect. Harvard Business Review 1995 (Nov-Dec).

14 Kaplan R, Norton D. Le tableau de bord prospectif. Paris: Editions d'organisation, Groupe Eyrolles, 2012.

15 ISO 10014. Quality management-Guidelines for realizing financial and economic benefits. Geneva: International Organization for Standardization, 2006.

16 Merlino Jl, Raman A. Health care's service fanatics. Harvard Business Review 2013;91:108-16, 50.

17 Owad WP Jr. Developing a customer-driven approach to quality improvement systems. Top Hosp Pharm Manag 1993;12:58-69.

18 Les forfaits par cas dans les hôpitaux suisses, informations de base pour les professionnels de la santé. SwissDRG SA.

19 Evaluation methods for the European Union's external assistance: evaluation tools. European Commission, 2006:4;99-108. [Working Document]

20 ISO 9004. Managing for the sustained success of an organization-a quality management approach. Geneva: International Organization for Standardization, 2009.

21 Règlement sur les établissements sanitaires et les établissements apparentés de droit privé dans le Canton de Vaud (RES). RS/VD 810.03.1. Le Conseil d'état du canton de Vaud, 2004

22 Ordonnance sur les médicaments (OMéd). RS 812.212.21. Le Conseil Fédéral Suisse, 2001

23 Gerbaud L, Laurens-Belgacem B, Antoniotti S, et al. L'utilisation des questionnaires de sortie, une enquête auprès de 7 centres hospitaliers. Santé publique 2002;14:21-30

24 Merrill P. Getting the best out of people, ISO 10018 aids ISO 9001 implementation. ISO Focus 2012;3:38-40

25 ISO/TC 176/SC 3. Système de management de la qualité-lignes directrices pour l'implication et les compétences du personnel. Geneva: Organisation Internationale de Normalisation, 2011. 